\title{
Circulação de artefatos entre cosplayers de Beagá e Vitória ${ }^{1}$
}

\author{
Mônica Rebecca Ferrari Nunes
}

Resumo: Este paper cartografa alguns acontecimentos relevantes para a compreensão da cena cosplay na região Sudeste do Brasil. Registra parte da interpretação dos dados coletados no Anime Fest Winter, Belo Horizonte (MG), 2013, e Vitória Anime Show, Vitória (ES), 2013, realizando uma análise comparativa e considerando a heterogeneidade da cena cosplay. Os estudos sobre a cidade contemporânea e as noções de circulação, assim como pesquisas sobre culturas juvenis articulam-se às reflexões sobre consumo material e midiático nesta cena, compondo a fundamentação teórica e metodológica sobre a qual se assenta este trabalho.

Palavras-chave: cosplayer e cosplay; cultura jovem; consumo.

Abstract: Circulation of artifacts among cosplayers in Belo Horizonte and Vitória - This paper maps some relevant events for an understanding of the cosplay scene in Brazil's southeastern state capitals. It discusses part of the interpretation of data collected during the Anime Winter Fest in Belo Horizonte, MG, in 2013, and the Vitória Anime Show in Vitória, ES, in 2013, based on a comparative analysis and considering the heterogeneity of the cosplay scene. Studies about the contemporary city and notions about circulation, as well as research about youth culture, are linked with reflections about material and media consumption in the cosplay scene, forming the theoretical framework and methodology on which this study is based.

Keywords: cosplayer; youth culture; consumption.

\section{Introdução}

A pesquisa Comunicação, Consumo e Memória: Cosplay e Culturas Juvenis, desde 2012, investiga a cena cosplay na região Sudeste do país, perscrutando regularidades e singularidades para avaliar modos de lembrar e de consumir artefatos, narrativas e

1 Trabalho apresentado ao GP Culturas Urbanas do XIV Encontro dos Grupos de Pesquisa em Comunicação, evento componente do XXXVII Congresso Brasileiro de Ciências da Comunicação, 2 a 5 de setembro de 2014. Este artigo é resultado parcial da pesquisa Comunicação, consumo e memória: cosplay e culturas juvenis (Chamada MCTI/CNPq/MEC/CAPES n. 18/2012), coordenada por Mônica Nunes e que conta com a participação dos 11 membros da Linha de Pesquisa em Comunicação, consumo e memória vinculada ao Grupo de Pesquisa Comunicação, consumo e entretenimento (Diretórios de Grupo do CNPq) junto ao PPGCOM-ESPM. 
personagens que inspiram os cosplayers - jovens que se vestem e atuam como personagens de narrativas midiáticas - a produzirem seus cosplays, contração de costume play, normalmente executados pelos próprios jovens.

Os eventos de cultura pop japonesa, como Anime Friends, entre outros, ${ }^{2}$ compõem o trabalho de campo. Tenho compreendido o ato de se vestir e atuar tal qual personagens midiáticos não só como prática de sociabilidade e de significação, mas também como propulsor de uma cena (STRAW, 2004), entendendo que a cena cosplay se faz graças à presença do costume, em seu caráter de objeto material e texto cultural (LOTMAN, 1996), em torno do que se constroem formas de sociabilidade e subjetividades, circulação de artefatos, afetos, memórias, identificações, relações geracionais, políticas e de consumo.

A cena imputa à cidade certa teatralidade pública graças ao fluxo de cosplayers e cosplays que potencializam esteticamente áreas urbanas: ruas e espaços insólitos como transportes coletivos se tornam palcos para a encenação de narrativas e materialização de personagens pelo indumento. Pode-se dizer, com base nas reflexões de Straw e Boutros (2010, p. 3-20), que essa cena não se configura apenas nos encontros convocados, restrita a uma localidade, mas se amplia com a circulação de formas estéticas como a roupa, a peruca colorida, as lentes de contato e afins; o corpo do cosplayer em sua dimensão corpo-mídia. Por sua vez, o encontro entre essas formas confere textura à vida cultural da cidade, atentando à cultura da circulação, definidora da própria condição urbana, pois a circulação não é um simples movimento de pessoas, ideias,

[...] é um processo cultural com suas próprias formas de abstração, apreciação e limitações, que são criadas pelas interações entre tipos específicos de formas circulantes e comunidades interpretativas construídas em torno delas. (LEE; LEPUMA apud STRAW e BOUTROS, 2010, p. 11)3

As comunidades interpretativas, entre elas, as instituições, códigos e práticas sociais, governam os vetores da mobilidade onde a circulação é fundamental. A ideia da circulação de formas estéticas evidencia a fase da vida dos objetos marcada pelo seu movimento no mundo, fato avaliado por Appadurai (2008), ao ponderar que as mercadorias têm vida cultural e que os significados das coisas estão postos em seus formatos, usos, trajetórias e biografias.

Sugere-se que o consumo na cultura da circulação signifique um consumo em trânsito, tratando especialmente da prática cosplay nas cidades. Em sua condição de prática social, confere mobilidade para os elementos materiais, artefatos consumidos para a confecção da fantasia, em torno dos quais as cenas ganham um desenho próprio constituindo-se unidades de cultura da vida urbana.

2 Anime Dreams 2012, 2013, SP; Anime Party 2012, 2013, SP; Anime Friends 2012, 2013, SP; Zelda Day 2013, SP; Cosrock Festival 2013, SP; Faraway Anime, 2013,SP, Anime Wings 2013, RJ; Anime Fest Winter 2013, MG; Vitória Anime Show, 2013, ES.

3 Tradução livre da autora. 
O comportamento de objetos que caracterizam a contemporaneidade, observados em seu movimento, aproxima-se daqueles vividos pelos jovens em algumas cenas. É curioso perceber que circulação, mobilidade, fluxo, flutuações, termos usados para definir a linguagem da cultura urbana, igualmente integram o campo semântico utilizado para reportar modos de sociabilidades juvenis. Almeida (2012) reconhece que em uma balada jovem,

\begin{abstract}
apesar dessas distintas modalidades da aproximação, diferenciadas pelos gêneros, uma regra é inescapavelmente comum a ambas: a circulação permanente. Meninos e meninas, quando querem "ficar" com alguém, não podem parar. Eles têm que andar, de estar em movimento todo o tempo, "rodando", "rodando". Não ficam no mesmo lugar esperando que alguém se aproxime. (ALMEIDA, 2012, p. 194; grifos meus)
\end{abstract}

Do mesmo modo, Bispo (2010, p. 29), ao analisar o "Orkontro Emo Oficial", encontro de adeptos do gênero emotional hardcore, apelidados de emos, que ocorre em um parque público do Rio de Janeiro, descreve: "eles fazem do Orkontro uma concentração de jovens agitada, que circula incessantemente, disparando flashs fotográficos (...) em bandos, os grupos de amigos passam freneticamente pelos acessos do parque" (grifos meus).

A circulação de objetos e jovens responde aos imperativos da velocidade e da multiplicidade de estímulos, compreendidos como códigos culturais da vida urbana, que também contaminam as cenas das culturas juvenis. Culturas performativas (PAIS, 2012; 2005), em que a expressividade por meio do corpo, da linguagem verbal, das vestes e atitudes, combina-se aos recursos cênicos, visuais, sonoros, hápticos aos quais estão expostos, permitindo inúmeros protagonismos. A cena cosplay, como outras cenas juvenis, revela sensibilidades performativas. Entretanto é preciso atentar à heterogeneidade nos modos de ser jovem (REGUILLO, 2012). Daí a importância do trabalho empírico, revelando singularidades e desvios, mesmo considerando o que muitas cenas têm em comum.

Desde 2012, compartilho com a comunidade acadêmica, as análises dos eventos de cosplayers na cidade de São Paulo (NUNES, 2012; 2013a; 2013b, 2014), porém, este paper registra parte da interpretação dos dados coletados em encontros pesquisados em diferentes cidades: Anime Fest Winter, Belo Horizonte, Minas Gerais, agosto de 2013, e Vitória Anime Show, Vitória, Espírito Santo, novembro de 2013, ${ }^{4}$ ambos com duração de dois dias, das 11 h00 às 19h00. O artigo analisa e interpreta a constituição das cenas, diferenças e semelhanças entre práticas e sociabilidades entre cosplayers de Beagá e Vitória, sob a perspectiva dos estudos sobre culturas jovens e consumo.

\title{
"Fazer cosplay é melhor do que drogas, do que álcool..."
}

Onde começa o trabalho de campo? Às portas do restaurante no qual almoço antes de iniciar a flânerie que me integra à cena, de onde avisto jovens descendo dos ônibus

4 As pesquisas de campo computaram 17 entrevistas em Belo Horizonte e 19 em Vitória. 
em frente ao Shopping Paragem, portando armas de papelão, perucas de muitas cores, em meio ao sábado da Rua Mário Werneck? Se a cena está expandida na cidade graças à circulação de artefatos, de afetos e memórias, o campo também está. Por isso, ainda fora do evento, fotografo, filmo panorâmicas que alcançam um grupo de adolescentes vestidos de preto empunhando latinhas de cerveja na calçada em frente à íngreme alameda que acessa a entrada da UNIBH, local do evento.

A convenção de Belo Horizonte, Anime Fest Winter 2013, foi a primeira a ser pesquisada depois daquelas da cidade paulistana. Havia participado de nove encontros, em São Paulo, e mesmo naqueles organizados por fãs, como o Zelda Day, que ocorreu em um parque público, ${ }^{5}$ ou no CosRock Festival - produzido por Camila Marotta, ${ }^{6}$ 27 anos, quem dispensa os seguranças para controlar o pequeno espaço reservado ao festival de cosplays e bandas de rock - nunca havia encontrado jovens consumindo bebidas alcoólicas, sequer nas imediações das faculdades e colégios onde normalmente os eventos acontecem. Para Camila, os seguranças não eram necessários, pois,

\begin{abstract}
aqui você vê um evento que é família. Vem pai, vem criança... Todo mundo está se divertindo, ninguém precisa beber, ninguém precisa usar drogas, não precisa bater em ninguém. É tranquilo. A gente não precisa nem de segurança porque o pessoal é tranquilo. (...) Se eu fizesse um show só de rock, tenho certeza que ia vir um pessoalzinho que ia querer arrumar confusão, ia querer beber cerveja e ia começar a causar. Mas em evento de animê você não vê isso. Você vê família tomando Mupy, pai com filho de cosplay e isso é legal. (Camila Marotta. Cosrock Festival 2013, SP)
\end{abstract}

Os episódios em torno do porte de bebida alcóolica durante o Anime Fest Winter 2013 adensam o argumento de que a cena cosplay é heterogênea, trazendo significantes para marcar a singularidade da cena mineira em meio às regularidades encontradas em São Paulo e Vitória, relacionadas ao discurso sobre álcool e drogas. Cesar Ikko, ${ }^{7}$ diretor-fundador do AnimeCom, empresa promotora do evento em Minas, relatou que para as próximas edições irá instalar bafômetros na entrada para evitar que jovens alcoolizados participem da convenção e narrou que naquela tarde, alguns já teriam "passado mal" e, por isso, retirados.

Porém, foi também possível reencontrar enunciados sobre a oposição entre bebida e cena cosplay. Entrevisto um rapaz mascarado, de roupa vermelha colada ao corpo. Hugo tem 22 anos, frequenta os eventos desde 2006, está vestido como Flash e me diz: "aqui é um centro de fazer amigos, é só alegria e não tem bagunça". Comenta ainda que fazer

5 Zelda Day é um dia escolhido para homenagear a série de jogos eletrônicos da Nintendo, The Legend of Zelda, em que se reúnem cosplayers dos personagens do game. A organização do encontro é feita por fãs que se comunicam pelas redes sociais. Esse evento ocorre no Rio de Janeiro, São Paulo e em outras cidades do Brasil. Disponível em <http://www.nintendoblast.com.br/2013/07/saiba-mais-sobre-o-zelda-day-um-dia.html>. Acesso em: fev. 2014.

6 Entrevistada no local do evento: Associação Beneficente dos Provincianos de Osaka Naniwa-kai. São Paulo (SP) em 9 de junho de 2013.

7 Entrevistado em .Anime Fest Winter, UNIBH, Belo Horizonte (MG) em 17 de agosto de 2013. 
cosplay "é muito melhor do que drogas, muito melhor do que álcool, te dá uma energia boa, você fica feliz, e tá tudo bem com seu corpo, com sua mente, e você não estraga sua vida pra ficar feliz, é um vício gostoso".

As falas de Hugo se repetem em muitos depoimentos coletados em São Paulo e Vitória. Na capital capixaba, circulou outra variante dos vícios abolidos: o cigarro. Jamile faz cosplay de Tomoyo, do animê Sakura Card Captors. A jovem se veste como colegial, tem uma fita vermelha nos cabelos negros e lentes de contato azuis. Conta que sua família não apoia o que faz, são muito religiosos, "acham que é coisa do capeta". "Na verdade", continua, "eles têm preconceito contra o Japão, acham que lá só tem gente doida". Entretanto, ela não se incomoda com a rejeição familiar e reforça seu bom comportamento ao explicar que "não faz nada demais" e prefere "comprar tecido do que um maço de cigarro" ${ }^{8}$

Mesmo considerando os episódios de Belo Horizonte, a bebida alcoólica, as drogas, o cigarro parecem não fazer parte da cena cosplay, não com a frequência em que estão presentes em outras cenas juvenis, em que o consumo de álcool e drogas sintéticas compõe os estímulos sensórios reveladores de novas sensibilidades e de uma hiperestesia, como afirma Fernanda Eugênio (2012).

Ao estudar a "cena carioca", essa autora salienta como a música, bebida, drogas, decorações arrojadas dos corpos e trocas de carícias inscrevem esses corpos jovens no instante, em uma volatilidade. Ainda que com menos estímulos, os emos passeiam pelo parque carregando suas mochilas ou "garrafas contendo bebidas alcoólicas" (BISPO, 2010, p. 29) e também se valem de carícias hetero ou homoeróticas para a pegação (ibid., p. 37).

Nem pegação, nem álcool, nem ecstasy. Não há eventos de animê na night. A cena cosplay atravessa o dia, mas à noitinha termina. Convida, mesmo assim, à circulação de corpos, afetos e artefatos exageradamente coloridos. Corpos hiperbólicos, se voltarmos às descrições de Pais (2012) sobre a excentricidade do vestir e o excesso de representação em muitos estilos jovens.

O que instiga é a complexidade dessa cena urbana e a dificuldade em generalizá-la. A pesquisa de campo esclarece que o corpo-mídia é multiplataforma para onde convergem as narrativas midiáticas. Narrativas e personagens são performatizados em tecidos, cores, materiais reciclados, maquiagens, misturas insólitas de substâncias que resultam em sangues falsos, óculos, toucas e uma infinidade de artefatos para a montagem do cosplay.

Não há dúvida sobre a importância que a imagem dos corpos adquire nessa cena, contribuindo para o argumento de que "os jovens investem em sua imagem porque as identidades são uma construção que se logra no visual, na linguagem, nas formas de comunicação e consumo com recurso a múltiplas estratégias cênicas" (CANCLINI apud PAIS, 2005, p. 55) - evidenciando a performance. Mas se as culturas juvenis são

8 Entrevistada em Vitória Anime Show, 16 de novembro de 2013, Clube Álvares Cabral, Vitória (ES). Manteve-se o registro obtido na entrevista desconsiderando a norma culta da língua portuguesa. 
performativas porque rejeitam as prescrições impostas pela sociedade, na cena cosplay parece haver negociações entre as performances expressivas, nômades, abertas ao devir e às prescrições sociais. O discurso sobre álcool e drogas reforçam esses acordos.

Vale aqui a perspectiva goffmiana ao tomar como metáfora para o desempenho dos indivíduos a ação teatral. A representação, isto é, a própria crença do indivíduo em seu papel, na impressão de realidade que tenta dar aos outros - precisa de uma fachada, um equipamento expressivo padronizado para a execução de uma prática. As representações podem ser socializadas dessa forma, ou seja, "moldadas e modificadas para se ajustar à compreensão e às expectativas da sociedade em que é apresentada" (GOFFMAN, 2011, p. 41). Interessa perceber o aspecto da idealização presente na socialização das representações como aquele que tende a produzir no indivíduo a incorporação de valores morais oficialmente reconhecidos.

No caso dos cosplayers pesquisados, o não ao álcool e às drogas pode ser lido como um modo de negociar sua incorporação às expectativas sociais de um mundo adulto, entendido como responsável, já distanciado do "loccus de transgressões toleradas" comuns às representações do ser jovem (EUGÊNIO, 2012). Os cosplayers são constantemente tachados como infantis por gostarem e representarem personagens de narrativas midiáticas comumente destinadas a crianças e adolescentes. Muitos são os jovens que têm dois perfis no Facebook, que não revelam aos amigos do trabalho que praticam cosplay ou mesmo são achincalhados quando estão montados.

As performatividades são vividas em espaços lúdicos, mas em fronteiras borradas onde produtos de consumo proibidos, como bebidas, cigarros e artefatos exagerados circulam para negociar e ao mesmo tempo negar expectativas e idealizações geracionais.

\section{"Brincar custa..."}

O Anime Fest acontece em Beagá em quatro edições ao longo do ano. A programação segue a toada das convenções paulistas, organizados pela concorrente da AnimeCom, Yamato Corporation: shows de bandas covers que tocam ritmos como o J e o K Pop, música pop japonesa e coreana respectivamente, animesongs, as trilhas sonoras dos animês; desfiles e apresentações de cosplays; estandes de produtos ligados à cultura pop, sobretudo, a nipônica; espaço para videogames e jogos de cards pokémons; apresentação de quiz sobre o universo dos animes.

O que difere a cena experimentada na UNIBH das outras já pesquisadas? Seu cenário, para usar a expressão de Goffman (2012), os cosplayers, formas de sociabilidade em torno do cosplay, a circulação de artefatos. O cenário é o ginásio esportivo da Universidade. Grande, barulhento, escuro. Visível são as marcas do japop: ${ }^{9}$ inúmeros estandes de vendas de quadrinhos japoneses, pôsteres de personagens de animês e mangás cobrindo parte das paredes.

9 Termo referido à cultura pop japonesa (LOURENÇO, 2010, p. 68). 
O eco dos alto-falantes ensurdecia a cena envolvida pelos mais variados sons, não apenas com o J Pop que tocava no palco montado no fundo do ginásio. Em certo momento, a música e a dança fervilharam os corpos com Marcarena e Harlem Shake transformando a cena cosplay em uma festa carnavalesca sem muitas máscaras, pois em Beagá são poucos os cosplays completos. Salientando que os cosplayers podem, durante os eventos, participar dos desfiles ${ }^{10}$ ou circular pelo espaço, normalmente em grupos, acompanhados pelos amigos e familiares.

A cena mineira parece mais pobre e com mais jovens negros que em Vitória. Entrevistei cosplayers e/ou amantes da cultura pop japonesa que estavam desempregados ou em empregos subalternos: auxiliar de entrega de supermercados, balconista de mercearia, auxiliar de metalurgia, vigilantes, vindos de regiões mais distantes do centro-sul da cidade, onde o evento ocorria: Venda Nova, Sete Lagoas, Boa Vista, Santa Luzia, só para citar algumas áreas mencionadas nos depoimentos. Muitos jovens não estudavam.

Novaes (2012, p. 106) reconhece que "ser pobre, mulher e negra ou pobre, homem e branco faz diferença nas possibilidades de 'viver a juventude' ", assim como o endereço em que moram: "abona ou desabona, amplia ou restringe acessos". Paula Cristina ${ }^{11}$ é uma jovem negra, atendente de telemarketing, tímida, como muitos dos cosplayers mineiros, e não quis ser filmada. Escolheu fazer cosplay de garota McDonald's porque "é mais parecido com a gente, deu pra fazer porque não existe, digamos assim, é um palhaço. Há um certo respeito por você porque você tá vestido como personagem".

O depoimento impacta, pois desvela à pesquisa outra possibilidade de interpretar os modos de pertencimento e reconhecimento sociais que o consumo dos artefatos materiais e simbólicos - midiático e afetivo simultaneamente - proporciona. Pais (2012, p. 14-15), ao se referir aos jovens consumidores de drogas ilícitas, explica que esses jovens reclamam por inclusão, pertencimento, reconhecimento, "daí suas performatividades, que não por acaso se ritualizam nos domínios da vida cotidiana mais libertos dos constrangimentos institucionais - os do lazer e do lúdico". Os jovens partícipes da cena cosplay também clamam por inclusão, pertencimento e reconhecimento, graças ao lazer, ao lúdico e às formas estéticas, à recriação dos personagens que realizam. Para os cosplayers, fazer o cosplay "bem feito" e ser reconhecido por isso se expressa por meio de pedidos de fotografias pelos outros frequentadores da cena.

No caso de alguns entrevistados em Beagá, como Paula Cristina, observa-se algo além do reconhecimento social obtido pelo disparo fotográfico. A jovem pode interpretar um palhaço, cujo rosto é coberto, "porque é mais parecido com a gente", "não existe", "dá pra fazer", isto é, não exige que ela seja branca e semelhante ao personagem. Sentese respeitada por encarnar uma celebridade midiática que teoricamente não tem rosto e por isso pode representá-la ou ser representada por ela - denotando a necessidade

10 Os desfiles de cosplays obedecem as tipologias diversas (NUNES, 2013a).

11 Entrevistada em AnimeFest Winter 2013, 18 de agosto de 2013. 
de inclusão social, de ter voz e visibilidade frequentemente negados aos jovens homens e mulheres, negros e pobres, por outro lado, obtidos graças à participação na cena, ao estatuto alcançado pelo viés da fantasia que permite que se sinta "como o personagem", 12 dispondo da importância e do valor simbólico que esses seres imaginários gozam na cultura do entretenimento e do consumo.

A relação entre negritude e personagens disponíveis na vasta rede de narrativas midiáticas é também mencionada em São Paulo. Dois relatos merecem ser transcritos: José Luiz, publicitário, 40 anos, vestido como Jedi Mace Winu -, Jedi negro da série Star Wars - afirma que só faz cosplay desse personagem para demarcar um posicionamento político: "as pessoas afrodescendentes não têm uma referência e quando têm se alegram em ver ${ }^{\prime \prime}{ }^{13}$ Do mesmo modo, a cosplayer Mariana, 19 anos, ${ }^{14}$ explica o motivo para ter escolhido a personagem Tempestade, ${ }^{15}$ do game $X$ - Men: "porque tem pouco cosplay que dá pra fazer devido a minha cor".

Ser negro e dispor de condições para um cosplay mais elaborado, como o fazem o publicitário e a jovem de São Paulo, não parece ser a regra na cena de Beagá. Notar a ausência numerosa de cosplays completos permitiu que no segundo dia do evento, decidisse entrevistar os jovens sem cosplay, mas que dispunham de artefatos sígnicos que indicavam pertencimento à cena: as camisetas pretas e/ou os adereços característicos de personagens, tais quais bottons, a capa ou a bandana de Naruto, o boné de Super Mário, a touca de bichinhos animados como Pikachú, personagens bastante comuns à cena cosplay. Muitos negros e brancos também circulavam com camisetas pretas.

O processo de transferência de significado cultural, na sociedade de consumo, (MCCRACKEN, 2012), em que o significado começa na cultura, desloca-se para os bens de consumo e alcança a vida dos consumidores graças a instrumentos que facilitam essa transferência, ajuda a entender porque as camisetas pretas e/ou adereços servem tanto aos que não têm recursos econômicos para fazer o cosplay quanto aos tímidos, sem coragem para montar os indumentos e os vestir. Como reporta Thiago, 22 anos, negro, morador de Boa Vista (MG), desempregado: "aqui todo mundo tem vontade de fazer cosplay, não faz porque não tem dinheiro ou por timidez". ${ }^{16}$

A camiseta preta, lisa ou estampada com cenas de filmes, nomes de jogos, de bandas, com personagens, etc, garante que, uma vez que os significados culturais tenham sido transferidos aos bens, os consumidores se apoderem desses significados para construir suas "noções de si mesmo e do mundo (...). Consumidores sempre acham significados

12 Sentir-se como o personagem que representam tem sido outra resposta regular quando os cosplayers são inquiridos sobre os motivos de praticarem cosplay.

13 Entrevistado em Anime Friends 2013. Clube de Marte. São Paulo (SP), 20 de julho de 2013.

14 Entrevistada em Faraway Anime, 1. Festival de Anime de Pirituba. Escola Santa Tereza, Pirituba (SP), 1 de dezembro de 2013.

15 Tempestade é uma personagem negra, de cabelos brancos e olhos azuis. É um ser mutante da segunda geração do X-Men. Disponível em: <http://www.xmenx.xpg.com.br/biografias_xmen/tempestade.html>. Acesso em: jan. 2014.

16 Entrevistado em Anime Fest Winter 2013, 18 de agosto de 2013. 
de gênero, classe, idade, estilo de vida, tempo e espaço nas suas posses e os usam para moldar aspectos do seu ser" (ibid., p. 117).

O consumo dessas camisetas não responde apenas à necessidade pragmática desses sujeitos, mas contribui com os significados culturais para as representações identitárias que constroem para si mesmos: ser jovem, roqueiro, nerd, otaku, em seus multipertencimentos, independentemente do que possam efetivamente consumir por meio da compra, que, em geral, "define 'quem é quem' no universo social" (FREIRE COSTA, 2004, p. 77), pois como lamenta Yuri, 20 anos, de camiseta preta lisa e sem qualquer adereço: "não faço cosplay porque tem outras coisas pra pagar. Brincar custa". ${ }^{17}$

Tais artefatos, bens de consumo, adquirem o significado simbólico do cosplay completo ainda que metonimicamente e não são exclusivos da cena em Beagá. Mesmo entre os jovens que não indicam, em seus enunciados, falta de posses, as camisetas são signos de pertencimento estético. Tornam-se cosplays mínimos e de algum modo configuram-se como signos de inclusão e reconhecimento, pois acobertados por essas roupas e/ou acessórios são considerados conhecedores da cultura pop japonesa; devem encontrar seus pares, comungar suas preferências, fazer amigos - uma das conquistas desses eventos que se mostram "um espaço de intensa sociabilidade" (LOURENÇO, 2010, p.70).

\section{"Se não brincar, que vida triste que vai ser..."}

Vale destacar que fazer amigos ou reencontrá-los, fazer cosplay em grupo - quando combinam de virem vestidos como personagens de um mesmo animê, jogo ou filme para encenarem as narrativas, tirarem fotos, dançarem, apresentarem-se nos desfiles - é um ato constante em todas as cenas pesquisadas na região Sudeste do Brasil.

Mas levando em conta as matizes da condição juvenil (NOVAES, 2012), deve-se enfatizar as singularidades da cena cosplay capixaba, observadas no Vitória Anime Show, e também apontar as semelhanças com a cena mineira.

O Clube Álvares Cabral, à beira mar, sedia o evento. O controle à entrada é fluido, simplificado e os cosplayers se espalham pela grama que cerca a casa central, avarandada, coberta por um amplo telhado de madeira, sugerindo intimidade. Na relva, há bancos, churrasqueiras. Avistam-se navios que entram e saem do canal. E o álcool não está presente na cena. Logo, sou tomada pela imagem de uma jovem alta, de shorts curtos, quase cobertos por uma longa peruca azul, caminhando de modo a deixar o mar no contra plano de seus passos. Estuda Design na Ufes e me conta que os cosplayers costumam se reunir em frente à Universidade, no Parque da Pedra da Cebola.

As condições juvenis de Carolina Chidori, seu codinome graças ao primeiro cosplay que fez e pelo qual ficou conhecida, iriam se repetir ao longo dos dois dias. Os depoimentos arrolados sugerem que a cena em Vitória reúne mais estudantes do ensino médio e universitários que em Belo Horizonte.

17 Entrevistado em Anime Fest Winter 2013, 18 de agosto de 2013. 
Como em todos os encontros pesquisados, os jovens circulam e dizem fazer novos amigos. Ana Carolina, 21 anos, estudante de Química, na Ufes, de Alegre, relata que faz cosplay porque é divertido: "encontrei um grupo do mesmo anime [que o de sua personagem] e a gente ficou se divertindo refazendo algumas cenas do anime e a gente fica assim o dia inteiro brincando (...) nunca vi nada de briga no evento, é aquela coisa gostosa, que dá vontade de tá ali participando".$^{18}$

Se os jovens da cena cosplay circulam por um mundo performativo, expressando-se por meio de artefatos coloridos, roupas extravagantes, máscaras de heróis infantis que convidam a ficar o "dia inteiro brincando" também respondem às prescrições e aos comportamentos de decoro (GOFFMAN, 2011), negociando códigos, como a recusa a bebidas alcoólicas sugere. Em Vitória, a presença dos jovens na própria organização dos eventos que consubstanciam a cena é maciça, evidenciando nova negociação: o trabalho aliado à ludicidade.

Cristiano, 24 anos, e William, 30, idealizadores do Vitória Anime Show, têm percursos diferentes: Cristiano, desde 2006, trabalha na realização de eventos para jovens, e aos poucos montou sua própria equipe e, junto com William, fã de cultura pop, criou o selo Vitória Anime Show. Muitos jovens cosplayers compõem o grupo: Juliana ${ }^{19}$ é cosplayer com trajetória além do estado do Espírito Santo, vencedora de algumas competições e se integrou à organização do evento como apresentadora dos desfiles de cosplays. Igualmente Fernanda, estudante de Arquitetura, 23 anos, premiada em concursos nacionais de cosplays, ${ }^{20}$ trabalhou como jurada nos concursos do evento. Bianca, 23 anos, radialista, também jurada, é cosplayer e jogadora de RPG, criadora de um blog sobre casais nerds, casada com Matheus, 26, publicitário, ${ }^{21}$ quem conheceu jogando RPG.

A pesquisa tem percebido, por meio do trabalho empírico, que a paixão infantil pelos animês, vistos pela extinta tevê Manchete, e depois pelos mangás responde à iniciação desses jovens à cultura pop japonesa que, para muitos, derivou para o desejo de ir às convenções e fazer cosplay. O mundo do trabalho parece corresponder à mesma extensão, e, talvez, por isso, muitos cosplayers tenham transformado a experiência lúdica em experiência lucrativa. Essa face da cena encontrada em Vitória tem se mostrado em São Paulo, a exemplo do CosRock Festival, já citado, e do Faraway Anime idealizado por Liliam Carvalho, ${ }^{22} 22$ anos, também cosplayer. Do mesmo modo, a presença de estandistas que foram cosplayers e hoje comercializam produtos relacionados ao universo pop tem sido comum.

Outra marca das relações entre o universo lúdico, expressivo e performático, e o mundo prescritivo do trabalho são o surgimento dos cosmakers, aqueles que criam

18 Entrevistada em Vitoria Anime Show, 17 de novembro de 2013.

19 Entrevistada em Vitoria Anime Show, 17 de novembro de 2013.

20 Fernanda de Oliveira Souza recebeu Prêmio Destaque WCS Brasil 2013. World Cosplay Summit Brasil- concurso nacional de cosplay organizado pela JBC. Entrevista em Vitoria Anime Show, 17 de novembro de 2013.

21 Entrevistado em Vitoria Anime Show, 17 de novembro de 2013.

22 Entrevistada em Faraway Anime de Pirituba, na Escola Santa Tereza (SP), 1 de dezembro de 2013. 
os costumes, muitos também cosplayers, como Júlio, ${ }^{23}$ que trabalha como técnico em informática, mas tem um ateliê onde executa armas, roupas, experimentando materiais diferentes, realizando seus próprios trajes e os comercializando.

As cenas pesquisadas em São Paulo já tinham revelado a presença de muitas pessoas "mais velhas" com seus cosplays. Falamos em uma prática jovem de fato, desconsiderando as determinações biológicas, mas sim, a dimensão cultural, histórica dessa categoria. Por isso não foi surpresa encontrar, na cena de Vitória, Maria do Carmo, ${ }^{24}$ vestida como maid, com suas filhas Luana e Lívia, como vocaloides, prontas para o desfile. Insólito foi receber das mãos de Maria do Carmo um cartão anunciando a loja de fantasias e cosplays recém-inaugurada na garagem de sua casa. De tanto costurar os cosplays para suas filhas, e, depois para si mesma, resolveu comercializar cosplays, além de participar dos desfiles, posar para muitas fotos e "viajar nas fantasias".

"É um evento de comércio também", conforme relata Matheus, porém, entrar na cena é "se desligar, entrar noutro mundo (...) se você não tem um escape, como pode ser criativo?", pergunta Bianca, e, completa seu argumento: "se não brincar, que vida triste vai ser". Aqui, o performático imiscui-se ao prescritivo e o consumo desvela-se na circulação de capital, de artefatos e afetos.

\section{Considerações finais}

As cenas pesquisadas trouxeram semelhanças relacionadas ao modo como os cosplayers de Beagá e Vitória constroem seus artefatos sob a forma estética do cosplay: trazem da internet imagens de referência para compor seus personagens, pesquisam, por meio dos tutoriais, como customizar perucas, fazer roupas, sangue, máscaras, etc.; ajudam uns aos outros; em sua maioria, relatam solidariedade. A participação familiar também é citada: mãe, tias, avós, pais, quando apoiam o que fazem, costuram, constroem acessórios. Muitos referem a estilistas ou costureiras, mas sempre participam do processo, ao menos com a feitura de adereços.

O comportamento nos eventos também é similar: circulam, fotografam, brincam, performatizam. Em sua maioria, rejeitam bebidas alcoólicas e cigarros. Frequentam a cena com amigos; fazem novos amigos, cultivam os antigos pelas redes sociais. Consomem produtos da cultura pop.

Porém, vivem suas juventudes de modo diverso. Ser estudante, sustentado pelos pais, e/ou estar empregado com atividades rentáveis permite usar cosplays completos ou mais elaborados. O consumo material de artefatos, de formas estéticas, entre os cosplayers de Beagá eVitória, não circula da mesma maneira, revela desigualdades sociais. O consumo simbólico, afetivo e midiático, cuida, entretanto, de garantir a brincadeira, ainda que brincar também custe.

23 Entrevista em Anime Fest Winter 2013, 18 de agosto de 2013.

24 Entrevista em Vitoria Anime Show, 16 de novembro de 2013. 
Mônica Rebecca Ferrari Nunes é docente e pesquisadora do PPGCOM-ESPM, SP. É doutora em Comunicação e Semiótica (PUC-SP) e pesquisadora do CNPq. Coordena a linha de Pesquisa Comunicação, consumo e memória vinculada ao Grupo de Pesquisa Comunicação, consumo e entretenimento.

monicarfnunes@espm.br

\section{Referências}

ALMEIDA, M. I. M. "Zoar" e "ficar": novos termos da sociabilidade jovem. In: ; EUGÊNIO, F. (orgs.).Culturas Jovens: novos mapas de afeto. Rio de Janeiro: Zahar, 2012.

APPADURAI, A. A vida social das coisas: as mercadorias sob uma perspectiva cultural. Rio de Janeiro: Editora da UFF, 2008.

BISPO, R. Heterotopias emo: notas etnográficas sobre desvios e inversões da juventude emocore no Rio de Janeiro. In: VELHO, G.; DUARTE, L. (orgs.). Juventude contemporânea: cultura, gostos e carreiras. Rio de Janeiro: 7 Letras, 2010.

EUGÊNIO, F. Corpos voláteis: afeto e consumo na "cena carioca". In: ALMEIDA, M. I. M; EUGÊNIO, F. (orgs.). Culturas Jovens: novos mapas de afeto. Rio de Janeiro: Zahar, 2012.

FREIRE COSTA, J. Perspectivas da juventude na sociedade de mercado. In: NOVAES, R; VANUCCI, P. (orgs.). Juventude e sociedade: trabalho, educação, cultura e participação. São Paulo: Editora da Fundação Perseu Abramo, 2004.

FREIRE FILHO, J. Reinvenções da Resistência juvenil: Os Estudos Culturais e as Micropolíticas do Cotidiano. Rio de Janeiro: Mauad, 2007.

GOFFMAN, E. Representação do eu na vida cotidiana. Petrópolis: Vozes, 2011.

LOURENÇO, A. L. Otakus: jovens brasileiros e cultura pop nipônica. In: VELHO, G.; DUARTE, L. (orgs.). Juventude contemporânea: cultura, gostos e carreiras. Rio de Janeiro: 7 Letras, 2010.

LOTMAN, I. Acerca de la Semiosfera. In: La Semiosfera I. Madri: Ediciones Cátedra, 1996.

MCCRACKEN, G. Cultura e consumo II; mercados, significados e gerenciamento de marcas. Rio de Janeiro: Mauad, 2012.

NOVAES, R. Os jovens de hoje: contextos, diferenças e trajetórias. In: ALMEIDA, M. I. M; EUGÊNIO, F. (orgs.).Culturas Jovens: novos mapas de afeto. Rio de Janeiro: Zahar, 2012.

NUNES, M. Consumo musical nas culturas juvenis: cosplay, mundo pop e memória. Revista Contracampo, Niterói, Contracampo, n. 25, p. 80-96, dez, 2012.

A cena cosplay: vinculações e produção de subjetividade. Revista Famecos (Online), v. 20, p. 430-445, ago., 2013a.

A Emergência da Cena Cosplay nas Culturas Juvenis. In: Significação. Revista de Audiovisual. n.41. vol. 41, pp 218-235. Junho 2014.

; BIN, M. A voz e o gesto performáticos juvenis: poesia e cosplay em São Paulo. Animus (Online), Santa Maria, v. 12, série 24, p. 359-376, 2013 b. 
PAIS, J. M. Jovens e cidadania. Sociologia, Problemas e Práticas, n. 49, p. 53-70, 2005. Disponível em: <http://www.scielo.oces.mctes.pt/scielo.php?pid=S0873-65292005000300004\&script=sci_arttext>. Acesso em: fev. 2014.

Buscas de si: expressividades e identidades juvenis. In: ALMEIDA, M. I. M; EUGÊNIO, F. (orgs.). Culturas Jovens: novos mapas de afeto. Rio de Janeiro: Zahar, 2012.

REGUILLO, R. Culturas juveniles: formas políticas del desencanto. Buenos Aires: Siglo Veintiuno Editores, 2012.

STRAW, W.; BOUTROS, A. (orgs.). Circulation and the city: essays on urban culture. Montreal: McGill-Queen’s University Press, 2010.

STRAW, W. Cultural Scenes. Loisir et societé/society and leisure, v. 27, n. 2, 2004. Disponível em: <http://strawresearch.mcgill.ca/straw/loisirarticle.pdf>. Acesso em: ago. 2013.

Artigo recebido em julho e aprovado em outubro de 2014. 